\title{
Perioperative Coagulation Management in a Patient with Congenital Afibrinogenemia during Revision Total Hip Arthroplasty
}

\author{
Tomas Simurda, MD ${ }^{1}$ Peter Kubisz, MD, DSc ${ }^{1} \quad$ Miroslava Dobrotova, MD, PhD ${ }^{1} \quad$ Libor Necas, MD, $\mathrm{PhD}^{2}$ \\ Jan Stasko, MD, $\mathrm{PhD}^{1}$
}

${ }^{1}$ Department of Hematology and Transfusiology, National Centre of Hemostasis and Thrombosis, Jessenius Faculty of Medicine in Martin, Comenius University in Bratislava, Martin, Slovakia

2 Department of Orthopedics, Jessenius Faculty of Medicine in Martin, Comenius University in Bratislava, Martin, Slovakia

Address for correspondence Tomas Simurda, MD, Department of Hematology and Transfusiology, National Centre of Hemostasis and Thrombosis, Jessenius Faculty of Medicine in Martin, Comenius University in Bratislava, University Hospital, Kollarova Str. N. 2, Martin, 036 59, Slovakia (e-mail: tsimurda@orava.sk).

Semin Thromb Hemost 2016;42:689-692.

We read with great interest the article by Casini et al ${ }^{1}$ describing clinical features and management of congenital fibrinogen deficiencies, which was published along with other interesting articles related to such disorders in a recent issue of Seminars in Thrombosis \& Hemostasis. ${ }^{2}$ We therefore wish to report the only case of congenital afibrinogenemia in Slovakia with a successful perioperative management of hemostasis during revision total hip arthroplasty.

Congenital afibrinogenemia is an autosomal recessive bleeding disorder that refers to the total absence of fibrinogen, as measured by an antigenic assay. ${ }^{1}$ This disorder is caused by variations in the FGA, FGB, and FGG genes, which encode the fibrinogen $A \alpha, B \beta$, and $\gamma$ chains, respectively. Afibrinogenemia is associated with homozygous or compound heterozygous mutations, and hypofibrinogenemia is usually linked with heterozygous mutations. ${ }^{3,4}$ The estimated prevalence of afibrinogenemia is around 1 in $1,000,000,{ }^{4}$ although in Slovakia we estimate it to be 1 in $5,000,000 .^{5}$

The commonest manifestation of the disease is bleeding from mucosal surfaces; however, musculoskeletal bleeding, gynecologic and obstetric complications, spontaneous bleeding, bleeding after minor trauma and during interventional procedures, or thromboembolic episodes have also been reported. ${ }^{6}$ Absence of immunoreactive fibrinogen is essential for the diagnosis of congenital afibrinogenemia. All coagulation tests that depend on the formation of fibrin as the end point, that is, prothrombin time (PT), activated partial thromboplastin time (aPTT), or thrombin time (TT), are infinitely prolonged. ${ }^{1,4}$ Fibrinogen replacement therapy, particularly the most widely used plasma-derived fibrinogen concentrate, is considered as the treatment of choice in spontaneous bleeding episodes and as prophylaxis before surgical procedures or against spontaneous bleeding in patients with congenital and acquired fibrinogen deficiency. ${ }^{1,7}$

We herein report the successful perioperative management of hemostasis during revision total hip arthroplasty in a 26year-old man we have previously reported with congenital afibrinogenemia and a homozygous point mutation in exon 4 (Gln180Stop) of $F G B$ gene. $^{8}$ Early after birth, the patient experienced umbilical cord bleeding and development of epidural hematoma and hygroma in the occipital region with the need of neurosurgical evacuation. In the patient's history, there were many further bleeding episodes, including repeated hemorrhage into joints, muscles, mucocutaneous bleeding, and bleeding into soft tissues. This patient was managed with prophylactic intravenous administration of fibrinogen concentrate at the dose of $2 \mathrm{~g}$ once a month from the age of 15 years. ${ }^{5}$ Since then, he had significant reduction in the intensity and frequency of spontaneous bleeding.

The patient developed coxitis, or inflammation of the hip, in August 2002 due to microbleeds into the joint capsule. Coxitis was one of the most devastating complications of the patient's disease, and the implantation of a total hip endoprosthesis appeared the only possible treatment option. This was performed in the patient at age 15 years. One day before surgery, laboratory screening indicated grossly prolonged results for PT, aPTT, and TT (all of them $>300$ s). Platelet count $\left(230 \times 10^{9} / \mathrm{L}\right)$ and hemoglobin $(151 \mathrm{~g} / \mathrm{L})$ were in the normal range; however, fibrinogen according to the Clauss procedure was undetectable.

Owing to the rarity of afibrinogenemia, little is known about the optimal perioperative management of patients with this disease, including the pharmacokinetics of fibrinogen published online July 29, 2016
Issue Theme Editorial Compilation II; Guest Editors: Emmanuel J. Favaloro, PhD, FFSc (RCPA), and Giuseppe Lippi, MD.
Copyright $\odot 2016$ by Thieme Medical Publishers, Inc., 333 Seventh Avenue, New York, NY 10001, USA.

Tel: +1(212) 584-4662.
DOI http://dx.doi.org/ 10.1055/s-0036-1585079. ISSN 0094-6176. 


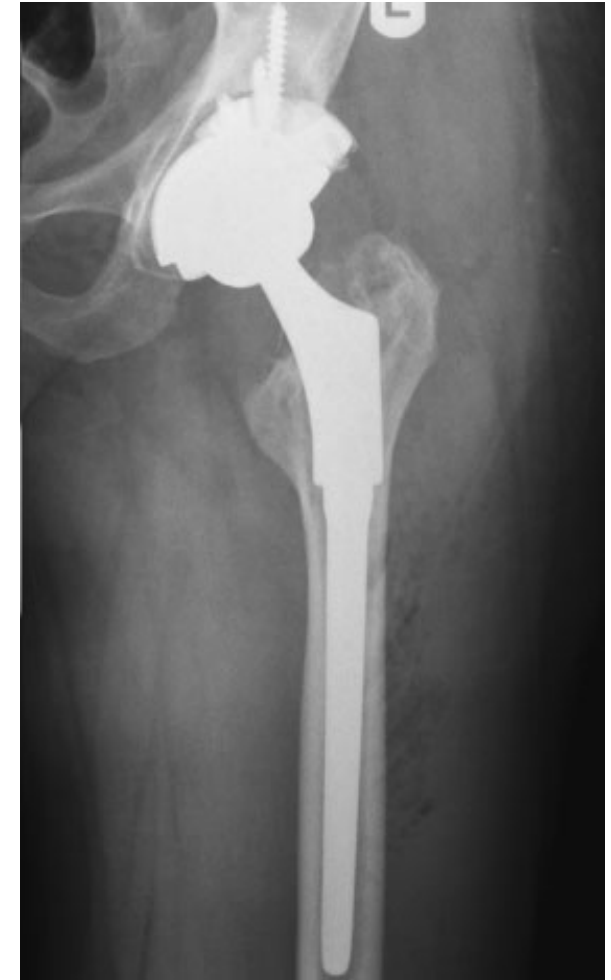

Fig. 1 Postoperative X-ray after the revision total hip.

concentrate. $^{9}$ In a survey conducted by Bornikova et al, the authors noted that for patients in surgical cases with satisfactory hemostasis, a plasma fibrinogen level ranging from 100 to 200 $\mathrm{mg} / \mathrm{dL}$ was achieved at the time of surgery. ${ }^{7}$ Preoperatively, the patient received fibrinogen concentrate (Haemocomplettan P, CSL Behring, Marburg, Germany) in the dose of $75 \mathrm{mg} / \mathrm{kg}$ ( $6 \mathrm{~g}$ of fibrinogen concentrate, weight of the patient $80 \mathrm{~kg}$ ). This dose increased the patient's level of fibrinogen after 2 hours to a rate corresponding to $170 \mathrm{mg} / \mathrm{dL}$. Intravenous administration of fibrinogen concentrate also led to a rapid change of previously unmeasurable PT, TT, and aPTT values to detectable values. These data were similar to those reported by Négrier et al. ${ }^{10}$ Thus, as demonstrated here and previously, patients can successfully be treated with a wide range of target fibrinogen levels and duration of treatment. This decision may be influenced by the severity of the deficiency and the invasiveness of the surgical procedure. The surgery itself lasted 3 hours under general anesthesia. During surgery, the patient received fibrinogen concentrate in the dose of $25 \mathrm{mg} / \mathrm{kg}$. The estimated blood loss was $800 \mathrm{~mL}$. The patient was given an intraoperative transfusion $499 \mathrm{~mL}(2 \mathrm{U})$ of packed red blood cells and $380 \mathrm{~mL}$ of auto transfusion. Immediately after surgery, the level of fibrinogen achieved was $110 \mathrm{mg} / \mathrm{dL}$. X-ray showed acceptable positioning and alignment of the implants (-Fig. 1). Postoperatively, the patient's fibrinogen levels were checked twice a day.

Twenty-four hours after surgery, fibrinogen concentrate was given to the patient at the dose of $37.5 \mathrm{mg} / \mathrm{kg}$ every 8 hours. The level of plasma fibrinogen was maintained above $130 \mathrm{mg} / \mathrm{dL}$. One day after surgery, fibrinogen concentrate was administered at the dose of $37.5 \mathrm{mg} / \mathrm{kg}$ every 12 hours with a targeted level of fibrinogen in the range of 130 to $150 \mathrm{mg} / \mathrm{dL}$. Two days after surgery, the fibrinogen concentrate administration was reduced to a dose of $25 \mathrm{mg} / \mathrm{kg}$ every 12 hours. This dose was given during the next 5 days. In this period, the fibrinogen activity was retained in the range of 170 to $210 \mathrm{mg} / \mathrm{dL}$. On the sixth and seventh day after surgery, the reduced dose of fibrinogen concentrate was continued at $12.5 \mathrm{mg} / \mathrm{kg}$ every 24 hours. During these days, the level of fibrinogen ranged as high as 120 to $140 \mathrm{mg} / \mathrm{dL}$. Between 8th and 12th day after surgery, we administered the fibrinogen concentrate at the dose of $12.5 \mathrm{mg} / \mathrm{kg}$ once every 48 hours. As the surgery required thorough hematological management, there was a need to ensure fine adjustment of the balance between the administration of fibrinogen concentrate and thromboprophylaxis. Accordingly, after surgery, the administration of fibrinogen concentrate was combined with lowmolecular-weight heparin (nadroparin) at the dose of $0.3 \mathrm{~mL}$ (2,850 IU) daily. Immediately after surgery, there were no signs or symptoms of excessive bleeding. The patient was discharged safely at the 12th day after surgery with a level of plasma fibrinogen above $50 \mathrm{mg} / \mathrm{dL}$ (- Fig. 2).

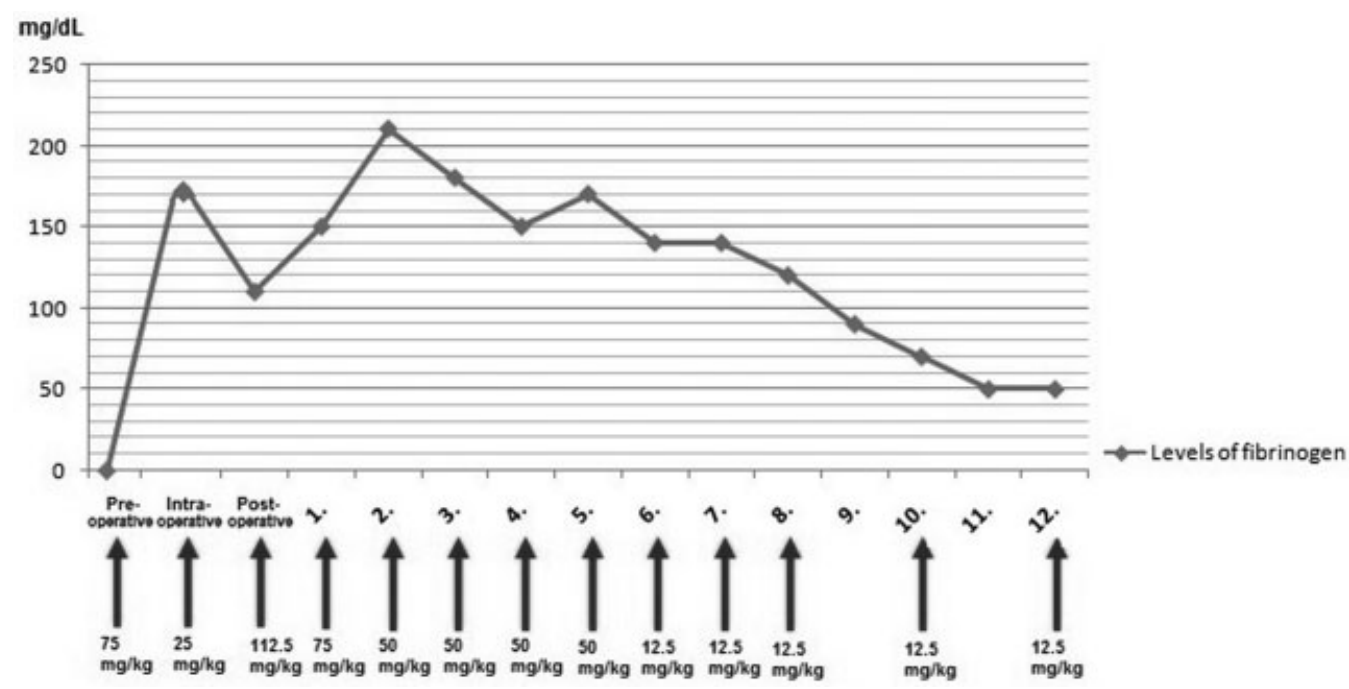

Fig. 2 The levels of fibrinogen measured preoperatively, intraoperatively, and postoperatively together with fibrinogen replacement therapy. 


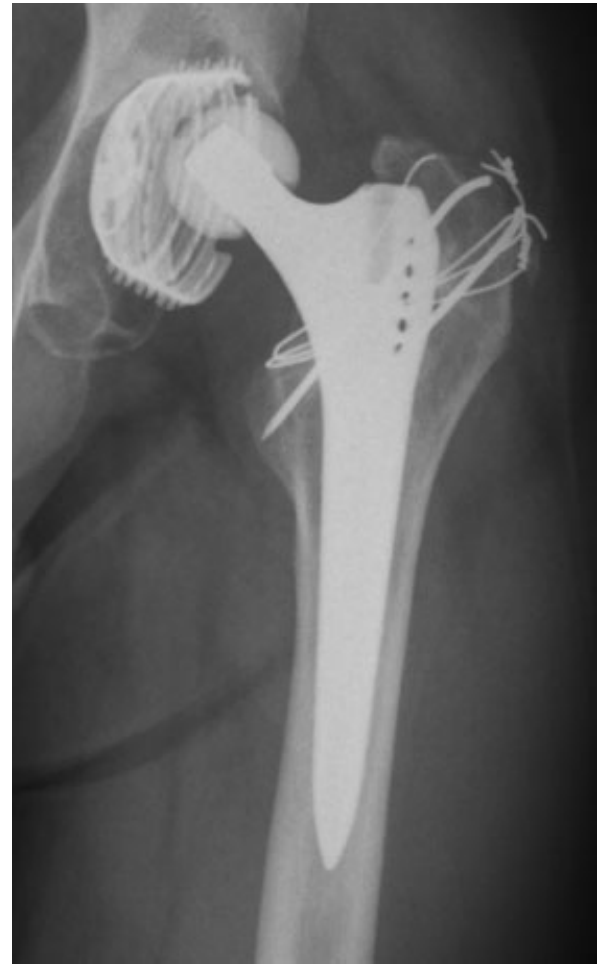

Fig. 3 Decentration of the femoral head and incipient osteolytic lesions below the acetabulum.

Regular orthopedic checks once a year were recommended. Unfortunately, 10 years later, from March 2014, the patient started to limp with a frequent and gradually disabling pain localized in the left hip. Control X-ray examination showed protrusion of the femoral head with the thinning of the inlay 4 to $5 \mathrm{~mm}$ and incipient osteolytic lesions below the acetabulum with the necessity of surgical revision (-Fig. 3 ).

The management of thrombotic complications in patients with afibrinogenemia is problematic because of their bleeding tendency. Some authors recommend use of compression stockings and low-molecular-weight heparin in patients with a history of thrombosis who are undergoing surgery. ${ }^{11}$ In patients who develop thrombotic complications following replacement therapy, some authors continue the latter if indicated and coadminister low-molecular-weight or unfractionated heparin. Our patient and members of the family have not experienced any thrombotic episodes. Furthermore, screening tests for thrombophilic mutations in the family have been negative. Therefore, thromboprophylaxis was applied at the dose of $0.3 \mathrm{~mL}$ daily only during hospitalization.

Our patient has otherwise been managed with prophylactic administration of fibrinogen concentrate at the dose of $25 \mathrm{mg} / \mathrm{kg}$ once a month from the age of 15 years before surgery. ${ }^{5}$ We managed the patient during intensive rehabilitation with prophylactic dose fibrinogen concentrate once a week within 2 months after surgery. At present, the patient is given a prophylactic dose of $25 \mathrm{mg} / \mathrm{kg}$ of fibrinogen concentrate once every 2 weeks and he is without any bleeding or thrombotic complications.

In conclusion, our results in this patient with congenital afibrinogenemia who underwent the successful repeated total left hip arthroplasty reaffirm the recommendation to tailor treatment to ensure a hemostasis balance between the replacement of clotting factor (fibrinogen concentrate) and thromboprophylaxis.

\section{Acknowledgments}

This work has a general support by departmental chairs. We would like to thank the support of projects Vega 1/ 0168/16, Grant Comenius University (UK / 334/2015), Martin Center of Biomedicine (BioMed Martin, ITMS 26220220187), and Agency for the Support of Research and Development (APVV) 0222-11.

\section{References}

1 Casini A, de Moerloose P, Neerman-Arbez M. Clinical features and management of congenital fibrinogen deficiencies. Semin Thromb Hemost 2016;42(4):366-374

2 Lisman T, de Moerloose P. The role of fibrinogen and factor XIII in hemostasis, and the identification and treatment of associated disorders. Semin Thromb Hemost 2016;42(4):331-332

3 Mannucci PM, Duga S, Peyvandi F. Recessively inherited coagulation disorders. Blood 2004;104(5):1243-1252

4 Neerman-Arbez M, de Moerloose P, Casini A. Laboratory and genetic investigation of mutations accounting for congenital fibrinogen disorders. Semin Thromb Hemost 2016;42(4):356-365

5 Simurda T, Stanciakova L, Stasko J, Dobrotova M, Kubisz P. Yes or no for secondary prophylaxis in afibrinogenemia? Blood Coagul Fibrinolysis 2015;26(8):978-980

6 de Moerloose P, Casini A, Neerman-Arbez M. Congenital fibrinogen disorders: an update. Semin Thromb Hemost 2013;39(6): 585-595

7 Bornikova L, Peyvandi F, Allen G, Bernstein J, Manco-Johnson MJ. Fibrinogen replacement therapy for congenital fibrinogen deficiency. J Thromb Haemost 2011;9(9):1687-1704

8 Simurda T, Snahnicanova Z, Loderer D, et al. Fibrinogen Martin: a novel mutation in FGB (Gln180Stop) causing congenital afibrinogenemia. Semin Thromb Hemost 2016;42(4):455-458

9 Peyvandi F. Results of an international, multicentre pharmacokinetic trial in congenital fibrinogen deficiency. Thromb Res 2009; 124(Suppl 2):S9-S11

10 Négrier C, Rothschild C, Goudemand J, et al. Pharmacokinetics and pharmacodynamics of a new highly secured fibrinogen concentrate. J Thromb Haemost 2008;6(9):1494-1499

11 Tziomalos K, Vakalopoulou S, Perifanis V, Garipidou V. Treatment of congenital fibrinogen deficiency: overview and recent findings. Vasc Health Risk Manag 2009;5:843-848 